\title{
LA CIENCIA EN MÉXICO EN EL SIGLO XIX: UNA APROXIMACIÓN HISTORIOGRÁFICA
}

\author{
Luz Fernanda Azuela \\ Instituto de Geografía de la UNAM (Universidad Nacional Autónoma de México) \\ Circuito exterior, Ciudad Universitaria - Apdo. postal 20-850. C. P. 04510. México, D. F.
}

\section{Rafael Guevara Fefer}

Facultad de Filosofía y Letras de la UNAM (México)

Ciudad Universitaria - C. P. 04000. México, D. F.*

\section{RESUMEN}

La historiografía ha desarrollado diferentes líneas de trabajo y distintas perspectivas para analizar el estudio de la ciencia hecha en México durante el siglo XIX. En la última década la comprensión de ese período ha experimentado un cambio como resultado de la profesionalización de la investigación en historia de la ciencia. Fases temporales y problemas que no habían suscitado atención en el pasado han sido ahora estudiados contribuyendo su revalorización a ofrecer una nueva imagen de la ciencia mexicana de ese período histórico. Este artículo recapitula los principales cambios que los autores han observado en los temas, interpretaciones y métodos que se han usado en las explicaciones históricas de la ciencia mexicana del siglo XIX. Para llevar a cabo este objetivo se efectúa un detenido repaso de las principales obras publicadas entre 1895 y 1996.

\section{SUMMARY}

Historical works on XIX ${ }^{\text {th }}$ century science in Mexico have developed on different interpretational paths and perspectives. In the last decade, the comprehension of the period has begun to change, as a result of professional research in the history of science. Long periods and subjects that were seldomly considered in the past, have been integrated, framing up a new image of mexican science in the last century. This article sums up the main changes we observed in the subjects, interpretations and methods that have been present in historical explanations of mexican science. To accomplish this purpose, we include an extensive review of the main works published between 1895 and 1996.

\footnotetext{
* En la localización de los textos colaboró Miguel A. Morales. También fue de extraoridinario va-
} lor el apoyo de las maestras Soledad Medina y Concepción Basilio, coordinadoras de las bibliotecas de los Institutos de Geología y Geografía de la UNAM, respectivamente. 


\section{INTRODUCCIÓN}

El estudio de la actividad científica en el siglo XIX en México ha sufrido una evolución singular en la que han prevalecido enfoques que, o bien han exaltado la consecución de grandes logros, o por el contrario los han minimizado, y apenas empieza a constituirse el corpus que dará cuenta de su desenvolvimiento. Pues aunque el estudio histórico de la ciencia mexicana del siglo XIX cuenta con una tradición centenaria, la investigación se ha dirigido al estudio selectivo de algunos temas y períodos, mientras que otros apenas empiezan a alborear en el seno de la ominosa "historia secreta" que denunciara Trabulse.

Entretanto, los historiadores a quienes dirigiera aquel reclamo, se han abstenido de seguir los esfuerzos por desvelar el secreto que se han realizado en los últimos años. Ejemplo de ello es la afirmación del historiador Luis González y González, quien en una reciente revisión sobre "el estado general de los estudios históricos en y sobre México", afirma que "antes de los años ochenta, nadie hacía historia del desarrollo científico". Afirmación tan rotunda, nos advierte la necesidad de dar a conocer la trayectoria de la historiografía de la ciencia de nuestro país, reto que enfrentamos hoy al abordar la que se refiere a nuestro campo de estudio: el siglo XIX.

Las causas del escaso impacto que han tenido los trabajos sobre la práctica científica mexicana en la conciencia de los historiadores - y aún de los especialistasresiden en la muy reciente incorporación de la historia de la ciencia como disciplina académica en nuestro país. Igual que en otras latitudes, se trata de un campo que apenas "está surgiendo de una prolongada y nada uniforme prehistoria"2, y en el que han concurrido filósofos, científicos, antropólogos, sociólogos e historiadores, en busca de datos para abordar los problemas de sus propias disciplinas. En el camino, algunos de ellos descubrieron un objeto de estudio autónomo, y emprendieron su investigación profesionalmente, dando un giro fundamental a la comprensión sobre el pasado científico de México, y en particular sobre su evolución en el siglo XIX.

De esta manera, la evolución historiográfica de la que nos ocuparemos, se relaciona estrechamente con el proceso de profesionalización de la propia historia de las ciencias. Por ello hemos elegido abstenernos de seguir la trayectoria de la historia de la medicina, especialidad que cuenta con una añeja tradición institucional en México, y que ha transitado por una senda alternativa que requeriría de un tratamiento independiente. En cambio, nos concentraremos en los estudios históricos sobre la ciencia mexicana del siglo XIX que se han elaborado en la última centuria, y que hemos podido agrupar estableciendo la secuencia, crecimiento y proliferación que configura

1 GONZÁLEZ, L. (1992): "La historiografía que nos rodea" en El historiador frente a la historia. Corrientes historiográficas actuales, México, UNAM-IIH, 29-38, p. 34.

2 KUHN, T. (1978): "La historia de la ciencia”, en SALDAÑA, J. J. (Comp.). (1989): Introducción a la teoría de la historia de las ciencias, México, UNAM, 195-213; p. 195. 


\section{LA CIENCIA EN MÉXICO EN EL SIGLO XIX: UNA APROXIMACIÓN HISTORIOGRÁFICA}

su linaje y aclara el proceso de conformación de la historia de la ciencia como campo de investigación ${ }^{3}$.

\section{LA CONCIENCIA TEMPRANA DE LA HISTORIA DE LA CIENCIA A FINALES DEL SIGLO XIX}

En las últimas décadas del siglo XIX, México vivió un momento de auge en el desarrollo de su actividad científica: se formaron sociedades especializadas; las publicaciones se multiplicaron; aparecieron las primeras instituciones de investigación y los hombres de ciencia dejaron su status de amateurs para convertirse en profesionales ${ }^{4}$.

El impacto que tuvieron estos acontecimientos sobre la vida social puede calibrarse en términos del entusiasmo que despertó la ciencia en aquella época, y que llevó a los intelectuales a depositar en ella sus esperanzas para conducir al país en un inexorable movimiento hacia la perfección. Los progresos de la ciencia aparecían como el elemento que había sustentado el sucesivo fortalecimiento de la razón humana, y cuyo cultivo permitiría alcanzar aquella meta. De ahí que se generara un movimiento intelectual que buscó rastrear su desenvolvimiento histórico, dando origen a la historiografía científica mexicana del siglo XIX en su propio tiempo.

Los primeros trabajos que incluimos en este período fueron realizados por los propios científicos y publicados, en su mayor parte, por las imprentas de la Secretaría de Fomento, ministerio al que pertenecían buena parte de las instituciones científicas de la época. Este fue el caso de la Biblioteca botánica mexicana: catálogo bibliográfico crítico de actores y escritos referentes a vegetales de México y sus aplicaciones desde la conquista de Nicolás León, que fue publicada a finales de siglo . La obra está conformada en gran parte por la hemerografía científica que se produjo en el siglo XIX, y se acompaña de una historia de las expediciones científicas. El mismo autor escribió los Apuntes para la historia de la Medicina en Michocán ${ }^{6}$, que

3 Es en este sentido en el que aceptamos la invitación de López Piñero de internacionalizar la historiografía de la ciencia de México, aunque posponemos la de integrar las corrientes historiográficas de la historia general de la ciencia y de la historia de la medicina. (v. LÓPEZ PIÑERO, J. M." (1992): "Las etapas iniciales de la historiografía de la ciencia. Invitación a recuperar su internacionalidad y su integración" en Arbor, CXLII, 21-67)

4 México se había incorporado al proceso que revolucionaba la práctica científica en todo el globo, y que se caracterizó por la formación de instituciones de investigación y el nacimiento del oficio de científico. Para la caracterización de estos hechos como revolucionarios, v. BARRY, B. (1987): Sobre Ciencia, Barcelona, Labor, 150 p.

5 LEÓN, N. (1895): Biblioteca botánico-mexicana: Catálogo bibliográfico, biográfico y crítico de autores y escritos referentes a vegetales de México y sus aplicaciones, desde la conquista hasta el presente, México, Oficina tipográfica de la Secretaría de Fomento, $372 \mathrm{p}$.

6 LEÓN, N. (1984): Historia de la medicina en Michoacán, (reedición), Morelia, UMSH, p. 94. 
representan un temprano intento por hacer historia regional de la ciencia, y en los que dedica la mayor parte de su estudio al siglo XIX. En relación con las ciencias de la Tierra, apareció la Bibliografía geológica y minera de la República Mexicana, de Rafael Aguilar y Santillán y la "Reseña del desarrollo de la Geología en México" de José Aguilera?.

Otro ejemplo es la Memoria para la bibliografía científica de México en el siglo $X I X,{ }^{8}$ que realizó Manuel de Olaguibel por encargo del Presidente para que se presentara en la Exposición Universal de París en 1889. Y aunque la intención del gobierno era que la memoria completara la imagen de la bibliografía científica mexicana del período, sólo se publicó el primer tomo dedicado a la botánica. Un año después, la misma Secretaría de Fomento publicó una valiosa historia del Colegio de Minería, escrita por Santiago Ramírez en forma de efemérides9.

Las páginas de las revistas científicas decimonónicas también dan fé del interés por recuperar el pasado de la ciencia mexicana, a través de la publicación de las biografías de los científicos de las diversas comunidades nacionales — como las escritas por el médico Manuel María Villada y el ingeniero Santigo Ramírez-. Las mismas publicaciones reeditaron algunos trabajos elaborados durante la Colonia y en los primeros años del siglo XIX, que habían aparecido en periódicos y revistas ya desaparecidas. La hemerografía incluye también esbozos históricos de instituciones científicas como el Jardín Botánico, el Colegio de Minería y el Museo Nacional entre otras.

Las primeras historias generales que registran nuestro pasado científico son la Historia de la Medicina en México desde la época de los indios hasta la presente y la Ciencia en México de Francisco Flores y Troncoso y Porfirio Parra respectivamente. ${ }^{10}$ La primera es un voluminoso tratado del devenir de las ciencias naturales en el siglo XIX, que incluye instituciones, personajes, aportes y desarrollos, proporcionando una imagen coherente sobre los cambios en la práctica científica a lo largo de .la historia del país ${ }^{11}$. La Ciencia en México de Parra, por su parte, constituye una interpretación positivista sobre el desenvolvimiento de la ciencia mexicana desde su

7 AGUILERA, J. (1905): "Reseña del desarrollo de la Geología en México", Boletín de la Sociedad Geológica Mexicana, 1a. época, 1, 35-117, México. AGUILAR Y SANTILLÁN R. (1898): Bibliografia geológica y minera de la República Mexicana, México, Oficina tipográfica de la Secretaría de Fomento.

8 Olaguibel, M. (1889): Memoria para la bibliografia científica de México en el siglo XIX, México, Oficina Tipográfica de la Secretaría de Fomento, $99 \mathrm{p}$

9 Ramírez, S. (1890): Datos para la historia del Colegio de Minería, México, Oficina Tipográfica de la Secretaría de Fomento.

${ }^{10}$ FLORES, F. (1982): Historia de la Medicina en México desde la época de los indios hasta la presente, 2 vols., México, Instituto Mexicano del Seguro Social, 1982, (Edición facsimilar). PARRA, P. (1903): "La ciencia en México" en SIERRA, J. México su evolución social, tomo 1, vol. 2, México, Ballescá, 417-466.

${ }^{11}$ El libro tiene un origen peculiar, pues Flores lo preparó originalmente como trabajo de tesis para recibirse de médico, meta que no consiguió por el retraso que significó la propia investigación. En cambio, el trabajo se convirtió con los años en una de la grandes obras históricas de todos los tiempos. 


\section{LA CIENCIA EN MÉXICO EN EL SIGLO XIX: UNA APROXIMACIÓN HISTORIOGRÁFICA}

pasado prehispánico, en la que prevalece la certidumbre de que el progreso de México depende del desarrollo de las ciencias.

Aunque no llegan a abandonarla, ambas obras superan la historia descriptiva y hagiográfica tradicional, y patentizan el espíritu nacionalista que las gestó. Pues aunque participan del eurocentrismo característico de esta etapa inicial de la historia de la ciencia Latinoamericana, en tanto que rastrean en nuestro suelo los indicios de lo que se consideraba "ciencia" según los cánones europeos de la época, sus investigaciones tienen también la intención de mostrar la larga tradición científica nacional ${ }^{12}$. En este sentido, y en virtud del enfoque positivista que comparten, las obras de Parra y Flores se inscriben en la tradición que se ocupa de estudiar la historia de la ciencia europea en México, perspectiva que no se abandonaría en buena parte del siglo $\mathrm{XX}^{13}$.

En 1910, y con el propósito de celebrar el centenario del inicio de la Guerra de Independencia, se editaron varias historias breves de las disciplinas científicas en el México independiente, que aparecieron un año después. Entre las que pudimos consultar se encuentran: Los progresos de la Astronomía en México desde 1810 hasta 191014, La ciencia arqueológica en México desde la proclamación de la independencia hasta nuestros días ${ }^{15}$, La evolución de la farmacia en México durante el primer siglo de nuestra independencia ${ }^{16}$, El desarrollo de las ideas científicas y su influencia social y política durante una centuria de vida independiente ${ }^{17}$, Apuntes para la historia de la estadística en México ${ }^{18}$, Importancia de la ingenieria en México ${ }^{19}$, Evolución de la

\footnotetext{
12 Véase SALDAÑA J. J. "Marcos conceptuales de la historia de la ciencia en Latinoamérica. Positivismo y economicismo", en SALDAÑA J. J., (editor) (1986): El perfil de la ciencia en América, México, Sociedad Latinoamericana de Historia de la Ciencia y la Tecnología-UNAM, 57-80.

${ }^{13}$ Ejemplo de ello, es La ciencia en México de Bravo Ugarte, en la que después de referirse a los orígenes de la ciencia occidental, el autor pasa a relatar cómo llegó y se practicó ésta en la Nueva España y el México Independiente. Véase BRAvo UgarTe J. (1967): La ciencia en México. Algunos de sus aspectos, México, Jus, $121 \mathrm{p}$.

14 LEÓN, L. G. (1911): Los progresos de la Astronomía en México desde 1810 hasta 1910, México, Tipografía de la Viuda de F. Díaz de León, 36 p.

15 MENA R. (1911): La ciencia arqueológica en México desde la proclamación de la independencia hasta nuestros días, México, Tipografía de la Viuda de F. Díaz de León, 15 p.

16 IRIARTE Y RICO, A. (1911): Evolución de la Farmacia en México durante el primer siglo de nuestra independencia, México, Tipografía de la Viuda de F. Díaz de León, 15 p.

17 GONZÁlEZ P. (1911): El desarrollo de las ideas científicas y su influencia social y política durante una centuria de vida independiente, México, Tipografía de la Viuda de F. Díaz de León, 14 p.

18 BARRERA F. (1911): Apuntes para la Historia de la Estadística en México 1821 a 1910, México, Tipografía de la Viuda de F. Díaz de León, 31 p.

19 PALACIOS L. (1911): Importancia de la Ingeniería en México, México, Tipografía de la Viuda de F. Díaz de León, $16 \mathrm{p}$.
} 
química en México ${ }^{20}$, Progreso de la geografía en México en el primer siglo de su independencia ${ }^{21}$ y Los progresos de la meteorología de 1810 a $1910^{22}$.

Aunque la mayoría de los trabajos relacionados son expresiones de las comunidades científicas en torno a la importancia de su labor para el beneficio de la sociedad y la nación, también contienen valiosa información sobre los hombres e instituciones que consolidaron la ciencia mexicana de principios del siglo XX. También está presente una conciencia bien desarrollada sobre el papel que desempeñaron los científicos decimonónicos en la conformación de las nuevas especialidades que comenzaban a establecerse en nuestro territorio ${ }^{23}$. Las obras revelan el paso del amateurismo hacia la profesionalización, que protagonizaron e impulsaron estos personajes, y el reconocimiento a su labor como los grandes maestros de su generación.

Tal vez la monografía dedicada al Progreso de la geografía, escrita por Isidro Rojas, en nombre de la Sociedad Mexicana de Geografía y Estadística (SMGE), es el trabajo de mayor valía. Se trata de una reseña muy completa de la geografía mexicana que - igual que las otras - rastrea los orígenes de la ciencia nacional en la Nueva España, y recoge los abundantes trabajos geográficos realizados a lo largo del siglo, buena parte de los cuales fueron elaborados por la propia SMGE24.

Como puede verse, los científicos de finales de siglo XIX y principios del XX se sirvieron de la historia para legitimar su actividad, inscribiéndola dentro del movimiento general de la ciencia en el mundo, así como dentro de una larga tradición científica que se había desarrollado en México y de la que eran herederos. Desafortunadamente, la tradición historiográfica que inauguraran se detuvo con el proceso revolucionario (1910-1940)25. Pues mientras los hombres de ciencia enfrentaban colosales dificultades para continuar con el desarrollo de su práctica en los nuevos esquemas organizativos, los historiadores emprendieron la reinterpretación del pasa-

20 CASTAÑARES, A. (1911): Evolución de la Química en México durante un siglo de nuestra independencia, Tipografía de la Viuda de F. Díaz de León, 1911, 10 p.

${ }^{21}$ ROJAS, I. (1911): Progreso de la geografría en México en el primer siglo de su independencia, Tipografía de la Viuda de F. Díaz de León, 50 p.

22 GonZÁlez García, I. (1911): Los progresos de la Meteorología en México de 1810 a 1910, Tipografía de la Viuda de F. Díaz de León, 23 p.

${ }^{23}$ Un caso interesante fue el de La Evolución de la Farmacia, que los farmacéuticos aprovecharon para exponer las dificultades que enfrentaban ante la ausencia de una escuela especial de farmacia y proponer su fundación.

${ }^{24}$ Desde 1833 la SMGE estaba encargada de efectuar los trabajos de reconocimiento, cartografía y estadística del país.

${ }^{25}$ El largo período incluye el proceso armado (1910-1920) y los gobiernos que se sucedieron, hasta el de Lázaro Cárdenas (1934-1940) que se ha caracterizado como parteaguas del proceso revolucionario al México moderno. 


\section{LA CIENCIA EN MÉXICO EN EL SIGLO XIX: UNA APROXIMACIÓN HISTORIOGRÁFICA}

do, privilegiando el desarrollo de la historiografía política. No hubo quien se ocupara de la historia de la ciencia ${ }^{26}$.

Había además otra razón de fondo: el proceso de conformación de la ciencia nacional, iniciado en 1824 con la primera Constitución, había fructificado justamente en el Porfiriato, periodo satanizado por la historiografía postrevolucionaria ${ }^{27}$. La historiografía que se generó después de la primera revolución del siglo $\mathrm{XX}$, se convirtió entonces en un cristal de observación de nuestro pasado político que marginó los hechos que protagonizaron los científicos del siglo XIX. Habían pasado a la "historia secreta de México".

\section{LA CIENCIA MEXICANA DEL SIGLO XIX EN LA HISTORIOGRAFIA DEL SIGLO XX}

\section{La emergencia de la historiografía de las ciencias}

La discontinuidad en la historiografía de la ciencia que se generó a raíz del proceso revolucionario, tuvo tres vías de recuperación: los artículos que aparecieron en revistas de divulgación científica, los trabajos que se realizaron por encargo para establecer la genealogía de las instituciones y las disciplinas científicas y los trabajos que se produjeron como resultado del impulso a la historia de la ciencia como campo de investigación en la segunda mitad de este siglo.

Respecto a la primera vía, es importante aclarar que en ausencia de órganos de difusión especializados, las revistas de divulgación han constituído una opción para dar a conocer los trabajos sobre historia de la ciencia. Sin embargo, y por sus características, los escasos artículos sobre el siglo XIX que aparecen en estas revistas, tienen un carácter desigual y en su mayoría representan una mínima contribución historiográfica. Las excepciones que trascienden por su buena factura son: "El Dr. Eduardo Prado y su mécanica analítica de 1898"28, "La Luz y las letras. Electricidad y literatura nacionales (1879-1905)"29, "El Diccionario Universal de Historia y

${ }^{26}$ Tal vez la excepción sea el folleto La biología en México durante un siglo de Alfonso L. Herrera. El científico, formado en el Porfiriato y partidario de la revolución, diferencia la biología mexicana prerevolucionaria y revolucionaria, señalando que los estudios de los científicos postrevolucionarios son de mayor alcance en el terreno de la biología. Véase HERRERA, A. L. (1921): La biología en México durante un siglo, México, s/e, $16 \mathrm{p}$.

${ }^{27}$ Como Porfiriato se designa al período transcurrido entre 1876 y 1910, durante el cual el país fue gobernado por el Gral. Porfirio Díaz, incluyendo la presidencia de su compadre Manuel González (18801884).

${ }^{28}$ PIÑA, E. (1987): "El doctor Eduardo Prado y su mecánica analítica de 1898”, en Ciencia, 38, 119-130.

${ }^{29}$ SCHNEIDER, L. M. (1993): "La Luz y las letras. Electricidad y literatura nacionales (1879-1905)», en Ciencia y Desarrollo, XIX, 71-75. 
Geografía, una empresa científico-cultural mexicana de mediados del siglo XIX"30, "Ciencia y política en la innovación tecnológica zacatecana a principios del siglo XIX"31 y "Antecedentes históricos de las escuelas de minas y de geología en México". Los autores se dividen entre historiadores y estudiosos de otras áreas, de modo que, en conjunto, está ausente el rigor crítico y metodológico de la especialidad, y su riqueza reside en la aportación de información bien documentada.

Este es también el caso de los trabajos que se elaboraron con el propósito de rescatar el pasado de las instituciones de investigación científica actuales y de las disciplinas que practican. Nuevamente se trata de meras recopilaciones de información sin un marco teórico explicativo adecuado y sin referencia a los trabajos que se han realizado profesionalmente. Algunos ejemplos de esta bibliografía sobre el XIX son: El Instituto de Geología, datos históricos ${ }^{32}$, Química en México ayer, hoy y maña$n a^{33}$, Historia de la Facultad de Química ${ }^{34}$, Relación histórica de los antecedentes y orígenes del Instituto de Biología ${ }^{35}$, Herbario Nacional de México ${ }^{36}$ e Historia del Departamento de Biología de la Facultad de Ciencias ${ }^{37}$.

Contemporáneamente a la publicación de estos trabajos, empezaron a dar frutos los esfuerzos de algunos hombres de ciencia que se empeñaron en la sistematización de los estudios históricos sobre la ciencia mexicana. Entre los que consideramos los príncipes de la historia profesional de la ciencia se cuentan Enrique Beltrán, José Joaquín Izquierdo y Eli de Gortari. ${ }^{38}$ Los dos primeros como fundadores de la Sociedad Mexicana de Historia de la Ciencia y la Tecnología y el tercero como seguidor de John D. Bernal, convencido del papel de la ciencia en el desarrollo histórico de México, se constituyeron en los pioneros de la nueva historiografía de las ciencias en nuestro país.

\footnotetext{
${ }^{30}$ PI-SUÑER, A. (1996): "El diccionario universal de historia y de geografía. Una empresa científico-cultural mexicana de mediados del siglo XIX", en Ciencia y Desarrollo, XXI, 59-67.

${ }^{31}$ García GonZÁleZ, F. (1995) : "Ciencia y política en la innovación tecnológica zacatecana a principios del siglo XIX”, en Ciencia y Desarrollo, XXI, 35-43.

32 SANTILLÁN, M. (1946): El Instituto de Geología, México, UNAM-Instituto de Geología, 13 p.

33 GARritZ, A. (1991): Química en México ayer, hoy y mañana, México UNAM-Facultad de Química, $520 \mathrm{p}$.

34 GARCÍA HERNÁNDEZ, H. (1985): Historia de la Facultad de Química, México UNAM-Facultad de Química, 295 p.

35 ORTEGA, M, et al. (1996): Relación histórica de los antecedentes y orígenes del Instituto de Biología de la Universidad Autonoma de México, México, UNAM-Instituto de Biología, 97 p.

36 DÁvila, P. y GERMÁN, M. T. (1991): Colecciones Biológicas Nacionales del Instituto de Biología. Herbario Nacional, México, UNAM-Instituto de Biología, $122 \mathrm{p}$.

${ }^{37}$ Hoffmann, A. (1993): Historia del Departamento de Biología de la Facultad de Ciencias, UNAM, México, UNAM-Facultad de Ciencias, $467 \mathrm{p}$.

38 Otros pioneros de la historiografía profesional fueron los españoles Germán Somolinos d'Ardois y Modesto Bargalló, quienes investigaron la ciencia novohispana.
} 


\section{LA CIENCIA EN MÉXICO EN EL SIGLO XIX: UNA APROXIMACIÓN HISTORIOGRÁFICA}

Izquierdo (1893-1974) fue un destacado fisiólogo y prolífico historiador de la medicina, en cuyo campo publicó 126 trabajos históricos entre 1921 y 1972, once de los cuales son libros ${ }^{39}$. Una de sus primeras obras es el Balance cuatricentenario de la fisiología en México ${ }^{40}$, estudio que rastrea el origen de la disciplina desde el siglo XVI, en la cátedra de prima de la Universidad Real y Pontificia de México, hasta el primer tercio del actual. Izquierdo se refiere a las instituciones, los textos y los planes de estudio en el intento por trazar su genealogía. También escribió La primera casa de las ciencias en México ${ }^{41}$, obra publicada en 1958, en la que expone el origen del Colegio de Minería y su desenvolvimiento durante sus primeros años, estableciendo nuevamente la idea — que sería retomada por la historiografía consecutivade que la ciencia nacional se perfiló desde los tiempos de la Nueva España. Para Izquierdo, el Colegio de Minería fue la cuna de las disciplinas e instituciones nacionales posteriores, en tanto que la primera institución científica moderna en nuestro territorio. La obra está sustentada en abundantes fuentes primarias, que se integran de acuerdo con los cánones de la historiografía occidental, en particular de Henry E. Sigerist, con quien Izquierdo mantenía una cercana amistad ${ }^{42}$.

A través de sus contactos con los historiadores de la ciencia de otras latitudes, Izquierdo logró perfeccionar su trabajo de investigación y consolidó una posición crítica para dirigir el desarrollo de la especialidad en México hacia su eventual profesionalización. En 1961 afirmaba que la recuperación del pasado de las ciencias

"no llegaría a tener sentido histórico mientras no llegara a iluminar las luces de la crítica adecuada, que de ninguna manera puede consistir en meros comentarios como los que creen hacer ciencia histórica "por vía de preocupación teórica", en un acto creador de "sentido absoluto", que atribuyen a aptitudes misteriosas transmitidas por herencia, o a procesos indefinidos que dejan ocultos tras el vocablo intuición." 43

Enrique Beltrán, contemporáneo de Izquierdo, fue el primer profesional de la biología en México y al mismo tiempo el primer historiador de la biología mexicana. Su enorme producción histórica puede consultarse en la Revista de la Sociedad Me-

\footnotetext{
39 Véase RODRÍGUEZ DE ROMO, A. C., "José Joaquín Izquierdo Raudón (1893-1974): Historiador de la Medicina", en RodríGUEZ-SALA, M. L. (editora). (1996): Tres Etapas del desarrollo de la cultura científico-tecnológica en México, México, Instituto de Investigaciones Sociales-UNAM, 85-108.

40 IZQUIERDO, J. J. (1934): Balance cuatricentenario de la fisiología en México, México, Ediciones Ciencia, VI+358 p.

${ }^{41}$ IZQUIERDO, J. J. (1958) La primera casa de la ciencias en México: el Real Seminario de Minería (1792-1811), México, Ediciones Ciencia, 271 p.

42 El Dr. Izquierdo no sólo se ocupó de la ciencia mexicana, también escribió artículos y libros sobre la ciencia europea. Véase (1936): Harvey, iniciador del método experimental, México, Ediciones Ciencia, XVII+398 p. y (1942): Bernard, creador de la medicina científica, México, UNAM, XXIV+328 p.

43 RODRÍGUEZ DE ROMO, A. C. (1996), p. 86.
} 
xicana de Historia Natural en su segunda época, en donde se encuentran textos dedicados a la historia de la biología nacional e internacional ${ }^{44}$.

Su obra La contribución de México a la Biología. Pasado, presente y futuro, es un texto de divulgación histórica, cuyo eje explicativo principal consiste en rastrear los orígenes de la biología mexicana desde las épocas prehispánica y colonial hasta el siglo XIX -idea que estaba presente en sus trabajos anteriores y que estructuró los posteriores-. Beltrán incurre en el error propio de la historiografía positivista, de recuperar los hechos del pasado que se consideran científicos en el presente, pero no deja de advertir que el contexto socio-histórico en el que se integran las ideas científicas, tiene un peso específico en su desarrollo. Al respecto advertía: "No hay que olvidar la decisiva influencia que las condiciones sociales han ejercido sobre la aceptación o el combate de las ideas científicas"45.

Las ciencias naturales en Michoacán es otro trabajo de interés del mismo autor, en este caso por tratarse de una muestra de su preocupación por la ciencia regional ${ }^{46}$. En él, Beltrán se ocupa de la labor científica de Juan José Martínez de Lejarza, Melchor Ocampo, Nicolás León, Eugenio Dugés y Manuel Martínez Solórzano, hombres que con sus esfuerzos en la investigación de las ciencias naturales durante el siglo XIX, contribuyeron a desarrollar la actividad científica michoacana y tuvieron un impacto a nivel nacional ${ }^{47}$.

${ }^{44}$ Las contribuciones de Beltrán a la historia de la ciencia suman más de ochenta. Algunas de importancia para la historiografía decimonónica mexicana son (1942): "La Gaceta Médica de México, 1865-1941, y sus aportaciones al conocimiento de la zoología", Gaceta Médica de México, 72, 580-590. (1943): "Datos y documentos para la historia de la ciencias naturales en México. Los estatutos primitivos de la Sociedad Mexicana de Historia Natural", Revista de la Sociedad Mexicana de Historia Natural (Revista SMHN), 4, 115-121. (1945): "Biología", en F. Palavicini, México, historia de su evolución constructiva, México, 3, 455-465. (1948): "La Naturaleza periódico científico de la Sociedad Mexicana de Historia Natural", Revista SMHN, 9, 341-346. (1951): "Panorama de la Biología mexicana", Revista SMHN, 12, 69-99. (1953): “Alfredo Dugès: un siglo después, 1853-1953”, Revista SMHN, 14, 157-168. (1960): "La science française au Mexique" dans Culture Française, París, 9, 9-22. (1966): "Textos mexicanos de botánica en el siglo XIX", Revista SMHN, 27, 267-272. (1968): "Alfonso L. Herrera (1868-1968): Primera figura de la biología mexicana", Revista SMHN, 29, 37-91. (1968): "El primer Centenario de la Sociedad Mexicana de Historia Natural", Revista SMHN, 29, 111-169.

45 BELTRÁN, E. (1944): "Lamarck y Geoffroy Saint-Hilaire: su obra y su tiempo" en Revista SMHN, V, p. 165

46 BELTRÁN, E. (1984): Las ciencias naturales en Michoacán, segunda edición, Morelia, Michoacán, Universidad Michoacana de San Nicolás de Hidalgo, 94 p.

${ }^{47}$ En 1990 se publicó Ciencia y Tecnología en Michoacán, obra que reúne 23 ensayos sobre el tema, y que da continuidad a la de Beltrán. Se trata de un volumen desigual, en el que destaca el texto de Luis Ortiz Arias, "La obra botánica del doctor Manuel Martínez Solórzano". Más recientemente apareció una antología de textos científicos del siglo XIX en Michoacán, precedida por una introducción histórica que alude a los personajes e instituciones que cimentaron la tradición científica michoacana. (V. SÁNCHEZ, G. (comp.). (1992): Ciencia y tecnología en Michoacán, Morelia, Universidad Michoacana de San Nicolás de Hidalgo, 440 p. Véase también SÁNCHEZ G. y NOMELÍ, E. (1996): Las contribuciones 


\section{LA CIENCIA EN MÉXICO EN EL SIGLO XIX: UNA APROXIMACIÓN HISTORIOGRÁFICA}

Su trabajo como impulsor de la historia de la ciencia mexicana —en el que se inserta su labor de divulgación-, fue crucial para la ulterior profesionalización de la disciplina. Beltrán fue el artífice del Primer Coloquio Mexicano de Historia de la Ciencia y la Tecnología que se llevó a cabo en 1963 con el objeto de realizar un análisis general del desarrollo de las ciencias de nuestro país. En el Coloquio participaron historiadores, científicos y filósofos, que acompañaron al pequeño grupo de historiadores de la ciencia que se había integrado hasta entonces. Los trabajos se reunieron en una Memoria, conformando un volumen desigual en el que se encuentran por un lado, las contribuciones de los historiadores que por primera vez incursionaban en la ciencia mexicana y por otro las de los científicos que intentaron reconstruir su pasado. En un tercer grupo, sobresalen los trabajos de Izquierdo, Beltrán y Maldonado Koerdell, cuya familiaridad y experiencia en la historia de la ciencia, proporcionó a sus contribuciones la estructura de corte académico de la especialidad, que está ausente en el resto del volumen ${ }^{48}$.

Las Memorias también incluyen un trabajo de Eli de Gortari, quien acababa de escribir la obra La ciencia en la historia de México, ${ }^{49}$ cuya influencia ulterior nos llevó a caracterizarle como príncipe de los estudios históricos de la ciencia mexicana. En ambos trabajos el autor utiliza el materialismo histórico como herramienta teórico-metodológica, con base en la convicción de que "desde su comienzo la ciencia se ha desenvuelto en estrecha relación con el progreso material de la sociedad" 50 .

De acuerdo con este esquema, La ciencia en la historia de México, reconstruye el desenvolvimiento de la ciencia en nuestro país desde la época prehispánica hasta el siglo XX. ${ }^{51}$ El objetivo del autor era "Determinar cuáles fueron los conocimientos científicos elaborados por los mexicanos en las distintas épocas, analizando las condiciones históricas que los hicieron surgir, las influencias recibidas o ejercidas en diversas ocasiones y por diferentes conductos, y la manera como dichos conocimientos se convirtieron en agentes activos para obrar sobre la vida social de México" 52 .

michoacanas a la ciencia mexicana del siglo XIX, Morelia, Universidad Michoacana de San Nicolás de Hidalgo, 1996, 396 p.)

${ }^{48}$ El Coloquio permitió advertir la necesidad de fomentar la investigación de la especialidad, y poco después se fundó la Sociedad Mexicana de Historia de la Ciencia y la Tecnología, por iniciativa del mismo Beltrán. Véase. BeltRÁn, E. (1963): Memorias del primer Coloquio Mexicano de Historia de la Ciencia, 2 vols., México, UNAM.

49 GORTARI, E. (1980): La ciencia en la historia de México, México, Grijalbo, 446 p. La obra fue publicada por primera vez en 1963 .

50 GORTARI, E. (1963): “Algunas notas características de la ciencia del México Prehispánico, en BELTRÁN, (1963), p. 47.

${ }^{51} \mathrm{La}$ obra tiene como antecedente un libro anterior, que se ocupa de la segunda mitad del siglo XIX, y que se integró a la obra general. (v. GORTARI, E. (1957): La ciencia en la Reforma, México, UNAM, 88 p.)

52 GORTARI (1980), p. 73. 
En lo que respecta a la interpretación del siglo XIX, La ciencia en la historia de México presenta dificultades derivadas del marco teórico, pues frente a los grandes logros que se alcanzaron en los institutos de investigación que se formaron en los últimos años de la centuria, y que la obra detalla, el autor concluye que las aportaciones se limitaron a una mera "acumulación de datos". ${ }^{53}$ Afirmación que se constituye en una anomalía metodológica, pues en el resto de la obra están ausentes los juicios valorativos a los aportes teóricos de los científicos mexicanos, destacando en cambio el papel de la práctica científica en la historia de México. ${ }^{54} \mathrm{En}$ el caso del siglo XIX, de Gortari dejó además pendiente la explicación del impacto que tuvo el proceso de institucionalización de las ciencias y el nacimiento del oficio de científico en la modernización del país.

Independientemente de las limitaciones explicativas que se derivan del marco teórico, y que ha detallado el análisis de Saldaña, ${ }^{55}$ la obra representa un viraje importante dentro de la historiografía mexicana por dos razones: en primer lugar, el enfoque materialista contextualizó el desarrollo de las ciencias en México, relacionándolo con factores políticos y económicos que habían estado ausentes en los trabajos que hemos referido, y abrió la puerta para la ulterior construcción de una historia social de la ciencias. ${ }^{56}$ En segundo lugar, la obra de Gortari colmó un enorme vacío historiográfico, proporcionando una imagen más detallada del devenir general de la ciencia en México, en la que se integraron prácticamente todos los trabajos que se habían escrito hasta entonces, por lo que hasta la fecha constituye un texto de consulta indispensable ${ }^{57}$.

\section{La nueva historiografia}

Hacia la década de los setenta y como resultado de los trabajos que hemos reseñado, así como de la infuencia que empezaban a tener los estudios que se realizaban en el exterior, la historiografía mexicana de las ciencias dio un nuevo giro: Roberto

\footnotetext{
${ }^{53}$ Congruente con su afiliación ideológica, Gortari condena la dictadura de Porfirio Díaz, y en el capítulo "La Ciencia positiva y su evolución" hace un balance negativo de la ciencia del período. (v. GORTARI (1980), 298-337).

${ }^{54} \mathrm{Al}$ respecto habría que agregar, que Gortari trata muy superficialmente períodos históricos completos, como es el caso del siglo XVII y de la primera mitad del XIX.

55 SALDAÑA, (1986), 57-80.

${ }^{56}$ Idem, 66-67.

57 No obstante, la obra fue recibida con reservas por parte de los historiadores de la ciencia como Beltrán, quien comentó que no se trataba de "una historia clásica de la ciencia, sino más bien [de] una sociología de la ciencia". (v. BELTRÁN, E. (1979): "Reflexiones sobre historiografía de la biología en México", en Anales de la Sociedad Mexicana de Historia de la Ciencia y de la Tecnología, México, SMHCyT-UNAM, 1-20; p. 7)
} 


\section{LA CIENCIA EN MÉXICO EN EL SIGLO XIX: UNA APROXIMACIÓN HISTORIOGRÁFICA}

Moreno de los Arcos emprendió el rescate de los textos científicos novohispanos ${ }^{58}$; Elías Trabulse comenzó a publicar trabajos sobre la ciencia en el siglo XVII ${ }^{59}$ y se empezó a conformar el equipo de investigadores que completaría la ambiciosa Historia de la Ciencia en México ${ }^{60}$, bajo su dirección.

El caso de Moreno de los Arcos representaba una singularidad dentro de la comunidad de historiadores mexicanos, a la que permaneció integrado pese a su interés profesional por la historia de la ciencia. Aunque el grueso de su obra se concentra en la época colonial, también contribuyó a la historiografía de la ciencia del siglo XIX, con un trabajo sobre uno de los grandes temas del período: el darwinismo. El trabajo -realizado con el propósito de participar en una reunión internacional sobre la difusión del darwinismo - rastreó su recepción en la bibliografía científica mexicana, y presentó los argumentos que esgrimieron los participantes en la polémica que se generó en torno a la revolucionaria teoría ${ }^{61}$. Años después dio a la imprenta La polémica del darwinismo en México: Siglo XIX ${ }^{62}$, en donde incorporó como introducción aquel trabajo, acompañándolo con una antología de textos escritos en el siglo XIX que ofrecen las diferentes posiciones del debate. Hasta la fecha, la obra continúa siendo única en su género, pues todos los autores que se han ocupado del tema continúan utilizándola como punto de partida ${ }^{63}$.

La Historia de la Ciencia en México de Elías Trabulse, por su parte, constituye sin lugar a dudas la obra más ambiciosa y completa que se ha publicado sobre el pasado científico mexicano. Está conformada por cuatro volúmenes independientes, cada uno dedicado a un siglo en particular, a los que se suma un quinto libro con índices y biografías. Los cuatro volúmenes incluyen antologías de textos científicos elaborados en cada período, que se organizaron por disciplinas en capítulos indepen-

\footnotetext{
${ }^{58}$ Los primeros textos de Moreno sobre historia de la ciencia se remontan a los años sesenta, y en la siguiente década comenzó a publicar las reediciones de las obras de los científicos del período ilustrado, a las que integraba un estudio introductorio. Véase AZUELA L. F. (1997): "Roberto Moreno de los Arcos y la Historia de las Ciencias", en Ciencia Ergo Sum, 4, 119-120)

${ }^{59}$ Ejemplo de ello es su artículo (1974): "Un científico mexicano del siglo XVII: Fray Diego Rodríguez y su obra", que apareció en Historia Mexicana, XXIV, 36-79.

60 TRABULSE, E. (1985): Historia de la ciencia en México: estudios y textos siglo XVI-XIX, 5 vols. México, Fondo de Cultura Económica-CONACYT.

${ }^{61}$ La reunión fue organizada por Thomas Glick, y se llevó a cabo en 1972. Los trabajos aparecieron en GLICK, T. (ed.). (1974): The Comparative Reception of Darwinism, Austin, University of Texas.

62 MoReno, R. (1984): La polémica del darwinismo en México. Siglo XIX, México, UNAMInstituto de Investigaciones Históricas, $384 \mathrm{p}$.

${ }^{63}$ Ejemplo de ello es el libro de Rosaura Ruiz, del que nos ocuparemos posteriormente. Moreno escribió también un ensayo donde aborda la ciencia decimonónica en el momento de su disolución a raiz de la crisis revolucionaria, que se concentra en el rumbo que tomó en los albores de este siglo. (v. el capítulo "Ciencia y Revolución Mexicana", en MORENO, R. (1986): Ensayos de historia de la ciencia y la tecnología en México, México, UNAM-Instituto de Investigaciones Históricas, 143-164.
} 
dientes. El primero contiene además, una introducción escrita por Trabulse que explica el desarrollo general de la ciencia mexicana desde la Conquista hasta el año de 1912.

Dotado de un profundo conocimiento sobre las corrientes historiográficas que conducían la investigación académica en aquellos años, Trabulse se acogió a la interpretación kuhniana, aunque tuvo la precaución de adaptarla a las peculiaridades del contexto local. De esta manera, a través del seguimiento de las tradiciones organicista, hermética y mecanicista en las sucesivas comunidades científicas, logra dar cuenta del desenvolvimiento del pensamiento científico en México hasta la consolidación del mecanicismo en el siglo XIX ${ }^{64}$.

Nuevamente se trata de una obra que se ocupa del desarrollo de la ciencia europea en México, de modo que están ausentes las referencias a las actividades científicas que se desarrollaron en los proyectos efectuados en determinados períodos históricos. ${ }^{65}$ Este es el caso de la práctica científica en la primera mitad del siglo XIX, período histórico caracterizado por grandes convulsiones políticas, a las que Trabulse atribuye el freno de los progresos que la ciencia había alcanzado durante la Ilustración, y el origen de su ulterior atraso:

\footnotetext{
"El desfasamiento en la investigación científica respecto de otras regiones del planeta, que había sido en gran medida eliminado en los últimos treinta años de vida colonial, empezó a percibirse nuevamente desde la segunda década del siglo XIX y ya no sería superado hasta nuestros días. El ritmo del conocimiento científico estaba sufriendo una aceleración vertiginosa en Europa en momentos en que México debía ante todo, organizarse como nación en lo interno y en lo externo[...] Además, no pocos de los intelectuales mexicanos mejor dotados para las ciencias hubieron de prestar sus luces a la organización política, económica y administrativa del país." 66
}

Respecto a la ciencia en el último tercio del siglo XIX, aunque detalla los personajes, las obras y las instituciones que prosperaron entonces, el autor apenas se distancia de la visión de Gortari —en cuya obra basa parte de su exposición-. Coherente con su propósito de historiar el desarrollo de la ciencia, Trabulse destaca el acopio de una gran "masa de datos" como la "contribución" mexicana al "corpus universal del saber científico en el cual México debía y podía ocupar un lugar"67.

Una valoración alternativa sobre los alcances de la práctica científica mexicana en el siglo XIX, empezó a generarse a finales de los años ochenta, a raíz de la intro-

\footnotetext{
${ }^{64}$ En relación con este proceso, el autor publicó: (1989): “Aspectos de la difusión del materialismo científico de la ilustración francesa en México a principios del siglo XIX", Quipu, 6, 371-385.

65 Para la discusión sobre la diferencia entre estos dos enfoques, v. LAFUENTE, A. (1986): "La ciencia periférica y su especialidad historiográfica" en SALDAÑA, (1986), 31-40.

66 TRABULSE, (1985), vol. 1, p. 170.

${ }^{67}$ Idem, p. 174.
} 


\section{LA CIENCIA EN MÉXICO EN EL SIGLO XIX: UNA APROXIMACIÓN HISTORIOGRÁFICA}

ducción de una nueva perspectiva metodológica, cuya aplicación en la última década ha transformado radicalmente la imagen del período.

Los primeros trabajos que condujeron hacia su reformulación se deben a Saldaña, quien ubicó en los textos constitucionales del México Independiente el papel capital que se otorgó a la ciencia en la edificación del país. De acuerdo con su texto " $\mathrm{La}$ ciencia y el Leviatán mexicano", desde el nacimiento de la nación,

\footnotetext{
“... los gobernantes mexicanos [...] buscaron gobernar con la razón y la ciencia y no de acuerdo a designios divinos, al igual que lo hacían para entonces los estados europeos más avanzados. El liberalismo político que enarbolaron los constituyentes se alimentó en gran medida del pensamiento ilustrado del siglo XVIII, pues para ellos fue la razón que condujo a la libertad". ${ }^{68}$
}

Con la publicación de este trabajo, Saldaña abrió una perspectiva metodológica que rastrearía el desarrollo de la ciencia mexicana del siglo XIX a partir de su vinculación con el Estado, que han recogido trabajos posteriores ${ }^{69}$. Estos destacan precisamente por rescatar los proyectos científicos que promoviera el Estado mexicano en las primeras décadas de la centuria, así como los que se desarrollaron bajo su impulso en épocas mal conocidas como el Segundo Imperio y el Porfiriato. Obviamente, la perspectiva metodológica privilegia el estudio de las instituciones y destaca el papel de las iniciativas gubernamentales en el desarrollo de la ciencia.

Entre los estudios que se ocupan de la primera mitad del siglo XIX, se encuentran: "Ciencia y Estado en México: 1824-1829" de Leonel Rodríguez; "El Instituto Nacional de Geografía y Estadística y su sucesora la Comisión de Estadística Militar" de María Lozano ${ }^{70}$ y "Minería y Política en México: el caso de la Química (1821-

68 SAldAÑA, J. J., "La ciencia y el Leviatán mexicano" en GonZÁlez ClaveráN, V. (editora). (1989): Actas de la sociedad mexicana de historia de la ciencia y de la tecnología, México, Sociedad Mexicana de Historia de la Ciencia y la Tecnología, 37-52

69 El mismo Saldaña habría transitado de la imagen de la ciencia presente en los textos de Gortari y Trabulse hacia la nueva conceptualización. En sus primeros trabajos sobre el XIX Saldaña mantenía la visión de una práctica científica limitada por su dependencia del Estado, que producía "conocimientos socialmente inútiles" Paradójicamente, tal afirmación entraba en contradicción con las investigaciones en proceso en aquellos años, que condujeron a la reformulación del siglo XIX, en las que el propio Saldaña participaba como director. (v. SALDAÑA, J. J. (1985): "La ideología de la ciencia en México en el siglo XIX", en PESET, J. L. La Ciencia moderna y el Nuevo Mundo, Madrid, CSIC-SLHCyT, 297-325 y (1989): "Science et pouvoir au XIXe siècle: la France et le Mexique en perspective" en PETITJEAN. P. et al, Science and Empires, Netherlands, Kluwer Academic Publishers, 153-164)

70 Ambos trabajos aparecen en un tomo editado por Saldaña, que incluye una extensa interpretación sobre el desarrollo de la ciencia mexicana desde la perspectiva analítica que ha desarrollado él mismo. (v. RODRÍGUEZ, L. "Ciencia y Estado en México: 1824-1829"; LOZANO, M. "El Instituto Nacional de Geografía y Estadísitica y su sucesora la Comisión de Estadística Militar” y SALDAÑA, J. J., "Acerca de la 


\section{LUZ FERNANDA AZUELA Y RAFAEL GUEVARA FEFER}

1867)" de Patricia Aceves y David W. Chambers ${ }^{71}$. Los tres trabajos reconocen en la actividad científica del período, la inercia que se generara a raíz de la difusión del pensamiento moderno durante la Ilustración, entendiendo este movimiento como el resultado de la interacción entre la comunidad científica metropolitana y colonial ${ }^{72}$.

El trabajo de Rodríguez se refiere al proyecto científico del Estado Mexicano durante el gobierno de Guadalupe Victoria (1824-1828), período en el que se buscó fortalecer a las instituciones de origen colonial como el Jardín Botánico, el Colegio de Minería y la Academia de San Carlos, y establecer otras nuevas como el Colegio Militar y el Museo Nacional de Antigüedades e Historia Natural. El artículo detalla la organización de comisiones en las que participó la comunidad científica para delimitar fronteras y levantar mapas y planos del territorio, así como registros de la flora y la fauna. También refiere la fundación del Instituto de Ciencias, Literatura y Artes, en 1823, tema que había tratado el autor en un trabajo anterior ${ }^{73}$. En conjunto, el artículo proporciona los datos que permiten documentar los esfuerzos que se realizaron para fomentar el desarrollo de la ciencia, que prometieran los textos constitucionales ${ }^{74}$.

historia de la ciencia nacional", en SALDAÑA J. J., (editor). (1992): Los orígenes de la ciencia nacional, México, UNAM- SMHCyT, (Cuadernos de Quipu 4, 141-186; p. 187-234 y 9-54, respectivamente.)

71 ACEVES, P. y ChAMBERS, D. "Minería y política en México: el caso de la química", en ACEVES, P. (editora). (1994): La Química en Europa y América (siglos XVII y XIX), México, Universidad Autónoma Metropolitana, (Estudios de historia social de las ciencias químicas y biológicas núm. 1), 223-254.

${ }^{72}$ Entre los trabajos que se ocupan de las peculiaridades del proceso de difusión y domesticación de la ciencia moderna en la Nueva España, destacan: MORENO, R. (1989): Linneo en México. Las controversias sobre el sistema binario sexual 1788-1798, México, UNAM-Instituto de Investigaciones Históricas, 279 p. y (1988): La primera cátedra de la botánica en México, UNAM-Sociedad Mexicana de Historia de la Ciencia y la Tecnología-Sociedad botánica de México, 145 p; GóNZALEZ GóNZALEZ E. "La reedición de las constituciones universitarias de México (1775) y la polémica antiilustrada" en AlVARADO, L. (1994): Tradición y reforma en la Universidad de México, México, UNAM-Centro de Estudios Sobre la Universidad, 57-108; BEUCHOT, M. (1986): Filosofia y ciencia en el México dieciochesco, México, UNAM- Facultad de Filosofía y Letras, 1996, 169 p; ACEVES, P. (1990): "La difusión de la química de Lavoisier en el Real Jardín Botánico de México (1788-1810)", en Quipu, 7, 371-385; TRABULSE, E. (1989): "Aspectos de la difusión del materialismo científico de la ilustración francesa en México a principios del siglo XIX", en Quipu, 6, 371-385 y RAMOS, M. P. (1994): Difusión e institucionalización de la mecánica newtoniana en México en el siglo XVIII, México, SMHCyT-Universidad Autónoma de Puebla, $159 \mathrm{p}$.

${ }^{73}$ Este trabajo representa el primer estudio publicado sobre la política científica en el nacimiento de la República. (v. RoDRíGUEZ, L. (1989): "El Instituto de Ciencias, Literatura y Artes de la Ciudad de México en 1826" en Memorias del Primer Congreso Mexicano de Historia de la Ciencia y de la Tecnología, México, SMHCyT, vol.2, 332-341)

${ }^{74}$ Posteriormente se han efectuado estudios independientes sobre los institutos científicos literarios, algunos de los cuales se ocupan de su surgimiento en los diferentes estados de la República, y otros que están más cerca de la historia de la educación que de la historia de la ciencia. Ejemplo de los primeros es: TORRE, F. (1995): "El Instituto de Ciencias de Jalisco, 1827-1834: más que una propuesta educativa" en Revista de la Universidad de Guadalajara, s/n, 28-33. Mientras que entre los segundos destacan: Ríos, R. (1994): "De Cádiz a México. La cuestión de los Institutos Literarios (1823-1833)" en Secuencia, 


\section{LA CIENCIA EN MÉXICO EN EL SIGLO XIX: UNA APROXIMACIÓN HISTORIOGRÁFICA}

Un resultado análogo deriva de la lectura del trabajo de Lozano sobre los primeros años del Instituto Nacional de Geografía y Estadística, en donde destaca el papel que se confirió al desarrollo de la investigación geográfica y estadística para el gobierno de la nación. El texto subraya la incidencia de los factores políticos en el devenir de la institución, y la importancia estratégica de sus tareas como el elemento que garantizó su supervivencia bajo nuevas formas de organización ${ }^{75}$.

Una visión alternativa es la del trabajo de Aceves y Chambers, en el que muestran que las sucesivas crisis políticas por las que atravesó el país entre 1821 y 1867 - las invasiones norteamericana y francesa, y las guerras intestinas- no impidieron la práctica científica y tecnológica dentro de nuestro territorio. Basándose en el estudio de la política minera y en particular del caso del Colegio de Minería, los autores concluyen que:

“... por lo que concierne a las actividades localizadas dentro de la esfera de influencia del Colegio de Minería, sabemos que se realizaron de manera sostenida (salvo pequeñas interrupciones) y que representan una continuidad sorprendente, dado el clima ocasionado por los trastornos políticos. Continuidad, que se manifestó tanto en la actualización de los planes de estudio frente al avance científico como en su adaptación a los proyectos del Estado"76.

Como puede verse, estos tres trabajos corrigen la noción de abandono de la práctica científica que presenta Trabulse, aunque por sus objetivos particulares no llegan a completar la imagen sobre el desarrollo de la ciencia en la primera mitad del siglo XIX. Su valor radica en su espíritu reformador y en la apertura de una rica veta historiográfica que otros autores empiezan a explotar77.

Un proceso semejante ocurre en relación con el estudio de la ciencia durante el Imperio de Maximiliano Habsburgo, período poco estudiado aún dentro de la histo-

nueva época, 30, 5-29 y (1994): "La secularización de la enseñanza del Colegio de San Luis Gonzaga en Zacatecas al Instituto Literario (1784-1838)" en Historia Mexicana, XLIV, 299-333. Más próximo a los objetivos de la historia de la ciencia: MAYER, L. y CHÁZARO, L. (1992): "La idea de Universidad en el último cuarto del siglo XIX. Los silencios culturales", en Quipu, 9, 327-348.

75 Un trabajo que complementa el de Lozano es "La geografía en México Independiente. 1824-1835...", en donde se alude al trabajo conjunto de intelectuales y políticos para integrar la geografía y estadística nacionales, que llevó a la creación de la carrera de geografía en el Colegio de Minería en 1843, así como a la refundación del Instituto como Sociedad Mexicana de Geografía y Estadística, en 1850. (v. RoDRíGUEZ, L. (1993): "La geografía en México Independiente. 1824-1835: El Instituto Nacional de Geografía y Estadística", en LAFUENTE, A., et al, Mundialización de la ciencia y cultura nacional. Actas del Congreso Descubrimiento y Mundo Colonial, Madrid, Doce Calles, 428-438.

76 ACEVES Y CHAMBERS, (1994), 253-254.

77 Obviamente se trata de investigaciones en proceso que se han dado a conocer en congresos, aunque existen dos trabajos publicados: la reedición de los Elementos de Orictognosia 1795-1805, de Andrés Manuel del Río, con un estudio histórico de la vida y obra del autor, de Raúl Rubinóvich y el estudio de Ana María Huerta sobre D. Antonio de Cal y Bracho, a los que nos referiremos posteriormente. 
riografía general de México, que ha centrado sus esfuerzos en referir la epopeya de la gesta republicana.

Hasta muy recientemente, la única referencia a la práctica científica durante la intervención francesa se había limitado a las contribuciones de Manuel Maldonado Koerdell en torno a la Commission Scientifique du Mexique ${ }^{78}$. En los trabajos que dio a la imprenta, Maldonado toma distancia de la condena historiográfica del período para recuperar el papel de la Commission en el desarrollo de la ciencia mexicana:

Si bien debe condenarse (muy especialmente por los mexicanos que aman la independencia de su país) las motivaciones que dieron origen a la expedición militar de Napoleón III contra México, desde el punto de vista científico la Comission Scientifique du Mexique dejó una obra de la mejor calidad y precursora del estudio de muchos aspectos de nuestra naturaleza y nuestra cultura ${ }^{79}$.

Con ello, logra rescatar la inexplorada riqueza que ha quedado encerrada entre las fauces de la censura nacionalista, e invita a estudiar los trabajos realizados por franceses y mexicanos a lo largo del efímero regimen imperial ${ }^{80}$. Y aunque la brevedad de los trabajos no permite profundizar en el impacto que tuvo la Commission sobre la ciencia del período, los datos que proporcionan sugieren la idea de una reactivación de la práctica científica relacionada con su presencia en el país ${ }^{81}$.

El único estudioso que ha recogido la estafeta es Alberto Soberanis, quien dio a la imprenta "La ciencia marcha bajo la égida de la guerra. Las relaciones científicas durante el Imperio de Maximiliano (1864-1867)"82, trabajo que da continuidad al estudio de Maldonado Koerdell. El artículo se sustenta en una exhaustiva investigación documental realizada en archivos franceses y mexicanos, cuya riqueza le per-

\footnotetext{
78 Maldonado-Koerdell, M. (1963): "La Comissión Scientífique du Mexique", en Memorias del Primer Coloquio Mexicano de Historia de la Ciencia, México, UNAM, 239-247 y (1965): "La obra de la Commission Scientifique du Mexique", en La Intervención Francesa y el Imperio de Maximiliano, México, Asociación Mexicana de Historiadores de América Latina e Instituto Francés de América Latina, 161-182 (consultado en sobretiro).

79 MALDONADO-KOERDELL, (1963), 246-247.

80 Ya Nicolás León afirmaba en 1895, que "la invasión francesa a México durante los años 1865 y 1866, [había traído] consigo un regular movimiento científico en todos los ramos de la ciencia". (V. LEÓN, N. (1895), p. 359).

${ }^{81}$ Para una interpretación inteligente del trabajo de Koerdell en el contexto de la historiografía del Segundo Imperio, v. QUIRARTE, M. (1993): Historiografia sobre el Imperio de Maximiliano, reeimpresión, México, UNAM, 202-203.

82 SOBERANIS, A. (1995): "La ciencia marcha bajo la égida de la guerra. Las relaciones científicas franco-mexicanas durante el Imperio de Maximiliano (1864-1867)», en Revista de la Universidad de Guadalaja$r a, \mathrm{~s} / \mathrm{n}, 49-60$. Otro texto de este autor en que se refiere a la comisión mexicana que colaboraría con la Commission es (1993): "La Commission Scientifique, Artistique et Litteraire fondée à Mexico en 1864 par le Maréchal Bazaine" en Bulletin de L'Academie Du Second Empire, 10, 13-15.
} 


\section{LA CIENCIA EN MÉXICO EN EL SIGLO XIX: UNA APROXIMACIÓN HISTORIOGRÁFICA}

mite superar la mera descripción de los hechos para explicar el surgimiento de la Commission Scientifique du Mexique en términos de los objetivos que expresaron uno y otro países y de las acciones que se efectuaron para llevarlos a cabo ${ }^{83}$. Después de detallar el proceso de organización y puesta en marcha del proyecto, el autor concluye señalando que a la caída del Imperio, "y con la experiencia de todos estos años de reorganización de la comunidad científica, la república retomó las propuestas hechas [...] por los científicos y por el mismo emperador"84. Con ello, Soberanis restablece la continuidad que fracturara la propia historiografia, y que impedía establecer el vínculo entre los proyectos científicos que se promovieron durante la intervención, con los que se prosiguieron a partir de la restauración de la República.

El trabajo que se ocupa de los cambios que se generaron en la práctica científica durante la República Restaurada y el Porfiriato es la obra Tres Sociedades Científicas en el Porfiriato. Las disciplinas, las instituciones y las relaciones entre la ciencia y el poder de Luz Fernanda Azuela ${ }^{85}$. El texto se refiere a la Sociedad Mexicana de Geografía y Estadística, la Sociedad Mexicana de Historia Natural y la Sociedad Científica "Antonio Alzate", agrupaciones que reunieron al conjunto de la comunidad científica entre los años de 1880 y $1912^{86}$. Sus fuentes principales son los artículos publicados en los órganos de difusión de las sociedades, a partir de cuyo análisis establece los cambios en la investigación científica durante treinta años, destacando el surgimiento de las nuevas especialidades. Para explicar este último proceso, Azuela relaciona la productividad en las diferentes áreas con el proceso de institucionalización de las ciencias que se verificó durante el período, y lo vincula con la participación de la comunidad científica en los proyectos gubernamentales. El trabajo proporciona una imagen congruente con las expectativas del título y deja pendiente la profundización del análisis del proceso de institucionalización de las ciencias, del que se han ocupado esporádicamente otros autores, así como su integración con un estudio sobre la educación científica, que surgió en aquellos años.

En lo que concierne al tema de la institucionalización de las ciencias, la bibliografía existente revela la ausencia de la noción del proceso que condujo a la creación y consolidación de las diferentes instituciones que aparecieron en esta etapa, dejando

${ }^{83}$ El punto mas fino de su discusión muestra las diferencias de fondo entre los objetivos políticos de la comisión francesa y los de la Academia Imperial de Ciencias que organizó Maximiliano.

84 SOBERANIS, (1995), p. 58.

85 AzUela, L. F. (1996) : Tres sociedades cientificas en el Porfiriato. Las disciplinas, las instituciones y las relaciones entre la ciencia y el poder, México, UNAM- SMHCyT-Universidad Tecnológica de Nezahualcóyotl, $217 \mathrm{p}$.

${ }^{86}$ Aunque el texto se concentra principalmente en los últimos 20 años del siglo XIX y los primeros 10 del siglo XX, al describirse la genealogía de las tres corporaciones científicas, la explicación arranca desde la restauración de la república en 1867. 
la impresión de que se trató de iniciativas aisladas ${ }^{87}$. Los trabajos publicados, por otra parte, no llegan a abarcar la totalidad de las instituciones y sólo se han estudiado el Instituto Médico Nacional ${ }^{88}$, el Instituto Geológico ${ }^{89}$, la Comisión GeográficoExploradora ${ }^{90}$ y el Observatorio Astronómico Nacional ${ }^{91}$.

En el pasado hubo por lo menos un intento de proporcionar una imagen mejor integrada que corresponde a Enrique Beltrán, quien dedicó la Primera Reunión Ordinaria de la Sociedad Mexicana de Historia de la Ciencia al estudio de las instituciones científicas mexicanas, cuyos trabajos fueron publicados en sus Anales. Sin embargo, los resultados fueron tan desiguales que J. Joaquín Izquierdo deslindó el cultivo de la historia de las ciencias como una especialidad que exigía el conocimiento histórico y el científico, y a la que no podrían acceder "personas que sólo [hubieran] cultivado historia de otro tipo, o de forma puramente literaria". ${ }^{92}$

Más recientemente, Saldaña y Azuela hicieron una recapitulación sobre el proceso de conformación de las sociedades científicas en México a lo largo del siglo XIX, relacionándolo en esta ocasión con el tránsito del amateurismo a la profesionaliza-

${ }^{87} \mathrm{La}$ institucionalización de las ciencias -en tanto que proceso- ha sido tratada por Azuela en: (1995): "El Instituto Médico Nacional como espacio de legitimación de la medicina mexicana tradicional" en ACEVES, P. (1995): Las Ciencias químicas y biológicas en la formación de un mundo nuevo, México, Universidad Autónoma Metropolitana, (Estudios de historia social de las ciencias químicas y biológicas, núm. 2), 359-372; "La Institucionalización de la meteorología en México a finales del siglo XIX" en RODRÍGUEZ-SALA, M. L. (1995): La cultura científico-tecnológica en México: nuevos materiales multidisciplinarios, México, UNAM-Instituto de Investigaciones Sociales, 99-106 y "La institucionalización de las ciencias en México durante el Porfiriato", en RODRíGUEZ-SALA, M. L. (1996), 72-81.

88 FERNÁNDEZ DEL CASTILlO, F. (1961) Historia bibliográfica del Instituto Médico Nacional de México (1888-1915), antecesor del Instituto de Biología de la Universidad Autónoma de México, México, UNAM.

${ }^{89}$ SalaZAR, L. (1929): El Instituto Geológico de México, México, Talleres Gráficos de la Nación, p. 103.

90 GARCíA, B. (1975): "La Comisión Geográfico Exploradora" en Historia Mexicana, XXIV, 485 555. Treviño, M. (1974): La Comisión Geográfico Exploradora del Ministerio de Fomento y la carta general de la República Mexicana a la escala 1:100.000, 1877-1914, México, Dirección General de Geografía y Meteorología, 21 p.

${ }_{91}$ Sobre el Observatorio, así como sobre otros temas relacionados con la astronomía mexicana, ha escrito abundantemente Marco Arturo Moreno Corral. (v. MORENO, M. A. (1986): “Algunos sucesos que dieron origen a la fundación definitiva del Observatorio Astronómico Nacional de México en 1878" en Quipu, 3, 299-310. (1988): "El observatorio Astronómico Nacional y el desarrollo de la ciencia en México (1878-1910)" en Quipu, 5, 59-68. (1991): "Telescopios que han influido en el desarrollo de la astronomía y la astrofísica en México" en Quipu, 8, 51-62. (1986): "Viaje de la Comisión Mexicana al Japón para la observación del tránsito de Venus de 1874" en MORENO, M. A. (comp.) La historia de la astronomía en México, México, Fondo de Cultura Económica, 169-189)

92 Con la excepción de los trabajos de Enrique Beltrán, Carlos Sáenz de la Calzada y Francisco Fernández del Castillo, se trata de estudios muy superficiales con una aportación historiográfica nula. (v. Anales de la Sociedad Mexicana de Historia de la Ciencia y de la Tecnología, núm. 1, México, 1969, 187 p. La reconvención de Izquierdo se publicó como "Sesión final" en las pp. 185-187) 


\section{LA CIENCIA EN MÉXICO EN EL SIGLO XIX: UNA APROXIMACIÓN HISTORIOGRÁFICA}

ción de la actividad científica. El artículo abarca desde la Primera República hasta el año de 1912, y retoma las ideas principales del libro de Azuela. ${ }^{93}$

En cuanto al estudio de la educación científica, el panorama historiográfico es muy raquítico, pues aunque se ha trabajado la conformación de los Institutos Científicos y Literarios, de la Escuela Nacional Preparatoria y de las escuelas profesionales ${ }^{94}$, algunos enfoques son ajenos a los objetivos y los métodos de la historia de las ciencias. La excepción es el trabajo de Ana Ma. Huerta, "Laboratorios químicos en Puebla, México, después de Lavoisier. Siglo XIX", que explica el proceso de formación de laboratorios químicos para los estudiantes de medicina y farmacia, que se inicia con la habilitación de espacios escolares y culmina con la instalación de verdaderos laboratorios ${ }^{95}$.

Otros enfoques que han sido utilizados para el examen de la ciencia en el siglo XIX, son los análisis de publicaciones científicas; los estudios de las disciplinas; las biografías y más recientemente la iconografía científica. En la primera categoría destaca el trabajo de Elsa Barberena y Carmen Block "Publicaciones periódicas científicas y tecnológicas mexicanas del siglo XIX: un proyecto de base de datos"96, que se ha convertido en un texto de consulta básica para los estudiosos del período. Publicado en 1986, cuando la investigación sobre la ciencia del XIX era aún incipiente, el artículo incurre en el error de agrupar revistas de diversa índole, que no necesariamente eran de carácter científico, pero en cuyos títulos aparecía la palabra "ciencia". La base de datos contiene 140 revistas y 103 periódicos en los que se encuentran la mayoría de las publicaciones científicas de aquellos años, y que se pueden consultar en los principales repositorios del país ${ }^{97}$.

Otro artículo del mismo tenor es el de Judith Licea, "Fuentes de información para el estudio de la farmacia mexicana del siglo XIX", en el que se hace un registro bi-

\footnotetext{
93 SALDAÑA, J. J. y AZUELA, L. F. (1994): "De amateurs a profesionales. Las sociedades científicas en México en el siglo XIX" en Quipu, 11, 135-172

${ }^{94}$ Además de los artículos sobre los institutos literarios que citamos anteriormente, veánse: CASTAÑEDA, E. (1995): "La ciencia en el Instituto Científico y Literario del Estado de México 18701910" en Coatepec, nueva época, 2. RODRíGUEZ, L. (1994): "La enseñanza en Sinaloa, durante el siglo XIX. La etapa inicial de la profesionalización de la ciencia" en Revista Interdisciplinaria de divulgación científica y tecnológica INTER, de la Universidad Autónoma de Sinaloa, nueva época, 3, 86-91. LEMOINE, E. (1970): La Escuela Nacional Preparatoria en el periodo de Gabino Barreda: 1868-1878, México, UNAM, 146 p. y BAZANT, M. (1993): Historia de la educación durante el Porfiriato, México, El Colegio de México, $297 \mathrm{p}$.

95 HUERTA, A. "Laboratorios químicos en Puebla, México, después de Lavoisier. siglo XIX", en ACEVES (1995), 281-292

96 BARBERENA, E. y BLOCK, C. (1986): "Publicaciones períodicas científicas y tecnológicas del siglo XIX: un proyecto de base de datos", en Quipu, 3, 7-26.

97 Como la Hemeroteca Nacional, la Hemeroteca del Archivo General de la Nación, la Biblioteca Sebastián Lerdo de Tejada de la Secretaría de Hacienda y Crédito Público y la Hemeroteca de la Universidad Autónoma de Chapingo entre otros.
} 
bliográfico de las farmacopeas mexicanas publicadas el siglo pasado ${ }^{98}$. El texto resulta valioso en términos de información, pero menos en términos interpretativos, comparado con el de José Joaquín Izquierdo, "Origins and Development of Mexican Pharmacopea"99 y el de Patricia Aceves, "Hacia una farmacia nacional: la primera farmacopea del México independiente"100.

Un giro interesante, en relación con la utilización de las publicaciones científicas del XIX, aparece en el estudio de Martha E. Rodríguez, "Las ciencias químicas y biológicas en las publicaciones científicas periódicas de medicina"101. En este caso, el trabajo sugiere rastrear la práctica de las nuevas áreas de investigación que no se habían profesionalizado, en las publicaciones de los gremios mejor consolidados. El texto constituye una aproximación al estudio de las disciplinas científicas, pero su brevedad impide profundizar en el tema ${ }^{102}$.

Dentro de este último campo casi todo está por escribirse, y los pocos trabajos publicados generalmente no corresponden a una perspectiva propia de la historia profesional de las ciencias. Ejemplo de ello es "Un siglo de la botánica en México" de Jerzy Rzedowski, uno de los botánicos más importantes de la actualidad, quien efectuó un trabajo digno de incluirse dentro de este examen historiográfico ${ }^{103}$. El propio autor autor aclara que su texto "no debe entenderse como una relación histórica formal ni exhaustiva sino más bien como ensayo por decantar y apreciar los rasgos y los personajes más sobresalientes de la botánica mexicana a partir de 1865 , basándose mayormente en datos de la literatura publicada". ${ }^{104}$ En este sentido, se trata propiamente de un testimonio en el que Rzendowski rescata la labor de los hombres que le precedieron en su quehacer, estableciendo una noción de continuidad dentro de la añeja tradición botánica.

\footnotetext{
98 LICEA, J., et al., "Fuentes de información para el estudio de la farmacia mexicana del siglo XIX" en ACEVES (1995), 353-358.

99 IZQUIERDO, J. J. (1952): "Origins and development of Mexican pharmacopea", Bulletin of the History of Medicine, Baltimore, Johns Hopkins University, XXVI, 51-70.

100 ACEVES, P., "Hacia una farmacia nacional: la primera famacopea del México Independiente" en ACEVES, P. (editora). (1995): Farmacia, historia natural y química intercontinentales, México, Universidad Metropolitana, (Estudios de historia social de la ciencias químicas y biológicas num. 3), 161-178.

${ }^{101}$ RODRÍGUEZ, M. E., "Las ciencias químicas y biológicas en las publicaciones periódicas de medicina", en ACEVES, (1995), 359-373.

102 Sobre disciplinas emergentes, pero con otro enfoque, se publicó el artículo "Bioquímica en la Facultad de Medicina. Antecedentes históricos: 1797-1957", que vincula sus orígenes con el desarrollo de la química en el siglo XIX, pero se centra propiamente en su institucionalización en el XX. (v. RoDRÍGUEZ DE ROMO, A. C., (1995): "Departamento de Bioquímica Facultad de Medicina, UNAM. Antecedentes históricos", en Ciencia, 46, 15-22.)

${ }^{103}$ RZEDOwSKI, J. (1981): "Un siglo de botánica en México", Boletín de la Sociedad Botánica de México, 40, 1-14.

104 Idem, p. 1.
} 


\section{LA CIENCIA EN MÉXICO EN EL SIGLO XIX: UNA APROXIMACIÓN HISTORIOGRÁFICA}

Dentro de la historia profesional de las ciencias, la botánica ha sido estudiada por Graciela Zamudio, quien se ha ocupado de su desarrollo en el período ilustrado, y recientemente dio a conocer las primicias de un trabajo mayor sobre su desenvolvimiento en el siglo XIX. El ensayo "Organización del saber botánico en México en el siglo XIX", se refiere al establecimiento de las instituciones; la enseñanza de la disciplina y los textos que se utilizaron; la difusión del conocimiento en publicaciones, tanto de divulgación como especializadas, así como a las sucesivas expediciones que se organizaron con el objetivo de levantar inventarios florísticos ${ }^{105}$.

Un texto que se aproxima a la historia de las disciplinas es Positivismo y Evolución: introducción al darwinismo en México de Rosaura Ruiz, que pretende explicar el nacimiento de la biología en México en la segunda mitad del siglo XIX, a través de la difusión del darwinismo en la comunidad científica e intelectual de aquellos años ${ }^{106}$. La autora se empeña en demostrar que la teoría darwiniana no fue plenamente utilizada en México y que tampoco se practicó la biología, en los términos en que se desarrollaba en Europa. La excepción fue Alfonso Luis Herrera, a quien caracteriza como biólogo porque a diferencia de sus contemporáneos, y como introductor del darwinismo, dejó "de describir lo vivo para tratar de explicarlo"107. El trabajo adolece del defecto de suponer que Herrera constituía una excepción dentro de la comunidad científica mexicana, pues aun cuando es cierto que fue uno de los más avanzados, también lo es que se desarrolló participando en las mismas tareas taxonómicas que efectuaron los naturalistas de la época. De modo que en todo caso se trata de un científico representativo del tránsito del naturalismo decimonónico a la biología del siglo XX. En lo que toca a la aceptación de la teoría darwiniana, su juicio es igualmente tajante, pues su condena sobre la reducida aplicación y aceptación en México en aquellos años, no está suficientemente matizada con la consideración de las dificultades que tuvo su difusión en otros países más avanzados ${ }^{108}$.

En cuanto al desarrollo de la farmacia, los trabajos más sólidos corresponden a Ana María Huerta, quien cuenta con varios artículos sobre el tema, y con el libro Los

${ }^{105}$ El trabajo fue presentado en el Coloquio "Materia Médica, Terapéutica y Farmacia Intercontinentales", Puebla, 16-19 octubre 1996, y será publicado este año por ACEVES, P. en el número 4 de la Colección Estudios de historia social de las ciencias químicas y biológicas.

${ }^{106}$ RuIZ, R. (1987): Positivismo y evolución: Introducción del darwinismo en México, México, UNAM- Limusa, 263 p.

107 Idem. p. 83.

${ }^{108}$ Entre los trabajos sobre el mismo tema, v. RUIZ, R. y AYALA, F. (1992): "Darwinismo y sociedad en México" en Siglo XIX Revista de Historia, nueva época, 12, 87-104. Para el análisis de la resistencia al darwinismo en nuestro país, véase el estudio de caso de BELTRÁN, E. (1988): "Alfredo Dugès y el transformismo", Quipu, 5, 49-57. Sobre el desarrollo de la biología mexicana, consúltese el estudio de historia regional de LEDEZMA, I. (1990): "Esbozo del desarrollo histórico de la biología en Puebla" en Quipu, 7, 93-126. 
boticarios poblanos: 1536-1825, en los que detalla diferentes aspectos de la práctica famacéutica en Puebla, tema que ha venido desarrollando durante varios años ${ }^{109}$.

En relación con las ciencias de la Tierra, el trabajo "La geografía en México en el siglo XIX. Institucionalización y profesionalización”, de Omar Moncada e Irma Escamilla contiene todos los elementos de un trabajo riguroso y metódico ${ }^{110}$. El artículo rastrea los orígenes de la disciplina en la práctica cartográfica novohispana, así como en los sucesivos planes de estudios hasta la creación y consolidación de la carrera de Ingeniero Geógrafo a lo largo del siglo XIX. También se refiere a la producción científica de los ingenieros geógrafos, estableciendo la distribución porcentual de las áreas de investigación que cultivaron, así como su vinculación con los proyectos gubernamentales en los que participaron ${ }^{111}$.

También de buena factura y dentro del mismo campo, se han publicado los artículos "Evolución de la Geología en México 1500-1929"112, de Zoltan Cserna y "Las Raíces de la Meteorítica en México" de Raúl Rubinóvich. ${ }^{113}$. El primero es una historia de la geología que se aborda aun antes del propio nacimiento de esta ciencia, y que detalla los sucesivos avances que efectuaron mexicanos y extranjeros, en el reconocimiento geológico del territorio. El artículo destaca el momento de consolidación de la disciplina a finales del siglo pasado, a partir de la creación del Instituto Geológico de México. El de Rubinóvich se refiere al nacimiento de la meteorítica en México, haciendo alusión a los estudios previos al siglo XIX y subrayando la participación de los científicos mexicanos en las discusiones que se generaron en todo el mundo en torno al fenómeno.

\footnotetext{
109 HuERTA, A. M., (1994): Los boticarios poblanos: 1536-1825, Puebla, Gobierno del Estado de Puebla, 281 p. y (1995): "La farmacia y la ciencias médicas en Puebla. 1795-1848", en ACEVES, (1995), p. 161-178. Por nuestra parte escribimos un artículo sobre la sociedad farmacéutica de México, en el que utilizamos la metodología de las redes sociales, y presentamos una visión alternativa sobre las relaciones entre la comunidad científica y el Estado, atendiendo a los mecanismos que operaron en el proceso de institucionalización de las ciencias. (AZUELA, L. F. y GUEVARA, R. "Las relaciones entre la comunidad científica y el poder político en México en el siglo XIX, a través del estudio de los farmacéuticos", ACEVES, P., Colección Estudios de historia social de las ciencias químicas y biológicas, núm. 4.

110 MONCADA, O. y ESCAMILLA, I. (1993): "La geografía en México en el siglo XIX. Institucionalización y profesionalización", en Ciencia, 44, 469-278.

111 Un trabajo igualmente sólido que complementa el de Moncada es la breve historia de la cartografía de Porfirio García de León, que el autor relaciona con el desarrollo de la geografía, revelando además su dominio de las técnicas cartográficas. (v. GARCÍA DE LEÓN, P. (1993) : "En busca de una imagen para el México del siglo XIX", en Historia del quehacer científico en América Latina, México, UNAMCentro Coordinador y Difusor de Estudios Latinoamericanos, 57-74)

112 CSERNA, Z. (1990): "La Evolución de la geología en México" en Revista del Instituto de Geología, 9, 1-20.

${ }^{113}$ RUBiNÓviCH, R. et al, (1992): "Las raíces de la Meteorítica en México" y "El mapa de los meteoritos de México", en Boletín de Mineralogía, 5, 85-90, respectivamente.
} 


\section{LA CIENCIA EN MÉXICO EN EL SIGLO XIX: UNA APROXIMACIÓN HISTORIOGRÁFICA}

En cuanto a la biografía científica, el género cuenta con antecedentes que se remontan al siglo XIX, a los que aludimos anteriormente, destacando una obra que continúa teniendo vigencia. Se trata de la que Santiago Ramírez dedicara al descubridor del vanadio, don Andrés Manuel del Río, que se convirtió en la principal fuente de las biografías que se realizaron con posterioridad ${ }^{114}$. Una de ellas es Andrés Manuel del Río y su obra científica ${ }^{115}$, publicada con motivo del segundo centenario de su natalicio, y que se inscribe dentro de la tradición de textos apologéticos que hacen aparecer al personaje en términos de su excepcionalidad dentro de su contexto histórico.

En cambio el estudio de Raúl Rubinóvich, que sirve de introdución a la reedición de los Elementos de Orictognosia de Andrés Manuel del Río, supera la actitud laudatoria y contextualiza la obra del científico español en su interacción con la comunidad científica novohispana y luego mexicana, en el tránsito de la Colonia a la Independencia ${ }^{116}$. Respecto al género, Rubinóvich señala que las biografías científicas constituyen "un enfoque particular que se complementa con otros de la investigación histórica", y en el que se "unifican y sintetizan coherentemente los diferentes aspectos de la vida, [el] aporte de la obra [y las] influencias del personaje estudiado en la sociedad de su época"117.

Con igual sentido articulador, se publicó recientemente el estudio de Ana María Huerta sobre D. Antonio de Cal y Bracho, a cuya biografía se suma el estudio de la botánica y la farmacia en Puebla en los primeros años del siglo XIX. En este caso, destaca además el hecho de que el trabajo se distancia del centralismo con que se realizan la mayoría los trabajos profesionales de historia de la ciencias en nuestro país, para ocuparse del caso poblano ${ }^{118}$.

Por nuestra parte hemos escrito el artículo "La obra del naturalista Alfonso Herrera Fernández" con la intención de penetrar en el medio de la comunidad de naturalistas de la época, estableciendo la relación entre las publicaciones del personaje y las diferentes actividades en las que se involucró. En este caso, la biografía se cons-

114 RamíreZ, S. (1891): Biografia del Sr. Andrés Manuel del Río, México, Imprenta del Sagrado Corazón de Jesús, 56 p.

115 BARgalló, M., et al. (1966): Andrés Manuel del Río y su obra científica. Segundo centenario de su natalicio (1764-1964), México, Compañía Fundidora de Fierro y Acero de Monterrey, 81 p.

${ }^{116}$ Río, M. A. del. (1992): Elementos de Orictognosia 1795-1805, reedición y estudio introductorio Raul Rubinóvich, México, UNAM, $70+200$ p.

117 Idem. p. 4-5. Paradójicamente, tal sentido del género biográfico está totalmente ausente en otra obra en la que participara el autor, y que se limita a registrar meros datos biográficos y referencias bibliográficas. (v. RUBINÓVICH, R., et al. (1991): José Guadalupe Aguilera Serrano. 1857-1941. Datos biográficos y bibliografía anotada, México, UNAM-Instituto de Geología, 116 p.)

118 HuERTA A. (1996): El Jardín de Cal. Antonio de Cal y Bracho, la botánica y las ciencias de la salud en Puebla, 1776-1833, Puebla, Gobierno del Estado de Puebla, 120 p. 
tituyó en el medio para definir los caracteres de la práctica científica en México en el último tercio del siglo XIX ${ }^{119}$.

Entre los extremos de la biografía apologética y la que se integra al contexto sociohistórico con fines explicativos, se sitúan algunos trabajos con intenciones reivindicatorias. Este es el caso del artículo de Enrique Beltrán, "Alfonso Luis Herrera. La primera figura de la Biología en México". El autor defiende la posición del controvertido Herrera como precursor de los estudios biológicos vanguardistas del pasado fin de siglo, pues se trató del único mexicano que incursionó en el estudio del origen de la vida desde una perspectiva materialista, en un medio intelectual adverso ${ }^{120}$.

También empeñados en la búsqueda de los precursores, se ubican buena parte de los trabajos que se han publicado en torno a la figura de Nicolás León, y que lo retratan como el padre de la antropología física, de la bibliografía científica, de la historia de la medicina mexicana, de la botánica y de muchas otras actividades ${ }^{121}$. Otras historias de la misma índole son: José Ramírez (1852-1904) vida y obra ${ }^{122}$, que reivindica al científico como precursor de los estudios bótanicos en México y "Químicos mexicanos" de Rafael Heliodoro Valle que describe muy brevemente a los padres fundadores de la emergente química moderna en nuestro territorio ${ }^{123}$.

Finalmente, una línea de investigación que ha empezado a desarrollarse, y que ya cuenta con trabajos muy terminados es la iconografía científica. Para Trabulse, autor de Arte y ciencia en la historia de México ${ }^{124}$, la iconografía se encuentra estrechamente relacionada con el desarrollo de la ciencia, por lo que sus historiadores tendrían que "inquirir acerca de cómo fueron expresadas las ideas científicas a través de las imágenes artísticas de [cada] época, lo que le [daría] una dimensión y una percepción novedosa en su acercamiento al pasado científico"125.

\footnotetext{
- $119 \mathrm{El}$ estudio además aclara la persistente confusión entre la figura del naturalista Alfonso Herrera y su hijo Alfonso Luis Herrera, en la que se ha incurrido hasta fechas muy recientes. (v. AZUELA, L. F. y GUEVARA, R., "La obra del naturalista Alfonso Herrera Fenández" en RodRíGUEZ-SALA (1996), 61-73.

${ }^{120}$ Se trata además de una historia testimonial, pues Enrique Beltrán fue discípulo de su objeto de estudio. (v. BELTRÁN (1968).

121 Véase, "Nicolás León y el Museo Michoacano", en BELTRÁN (1984), 65-82. VÁZQUEZ, P. (1984): "Estudio biobibliográfico sobre el doctor Nicolás León" y FERNÁNDEZ DEL CASTILLO, F. (1984): "El doctor Nicolás León, historiador médico de México" en LEóN, N., Historia de la Medicina en Michocán, Morelia, UMSH, 15-64. También se puede consultar en los Anales del Instituto Nacional de Antropología e Historia, 12, 1959, 33-71, artículos que versan sobre León, escritos por Antonio Pompa y Pompa, Manuel Maldonado- Koerdell, Germán Somolinos d'Ardois y Javier Romero, con motivo de un homenaje.

122 FLORES, H. y OCHOTERENA, H. (1991): José Ramírez (1852-1904) vida y obra, México, UNAMInstituto de Biología, 102 p. (Cuadernos 11).

123 Heliodoro VAlLE, R. (1954): "Químicos mexicanos", Historia mexicana, IV, 114-123.

124 TRABUlSE, E.(1995): Arte y ciencia en la historia de México, México, Fomento Cultural Banamex, $269 \mathrm{p}$.

125 Idem, p. 21.
} 


\section{LA CIENCIA EN MÉXICO EN EL SIGLO XIX: UNA APROXIMACIÓN HISTORIOGRÁFICA}

La obra recoge los mismos postulados metodológicos de la Ciencia en México, y explica su devenir en términos del análisis "de la naturaleza de los paradigmas que forman las grandes tradiciones científicas" 126 . En su relación con la iconografía, Trabulse señala que "como derivación lógica de la adopción de ciertos paradigmas, cada una de las épocas que [se delimitan en la obra] se caracteriza por poseer un lenguaje peculiar y una iconografía propia, indisolublemente unidos a las creencias científicas de una comunidad determinada de hombres de ciencia"127. La obra está dividida en dos partes, la primera que introduce el tema de la relación entre la imagen artística y el desarrollo científico, con un apartado que resume el desarrollo de la ciencia del siglo XVI al XIX. Y la segunda que recoge las imágenes de la iconografía científica mexicana en dos apartados: uno dedicado a las ciencias biológicas y físicas y otro a la cartografía. Cada uno de ellos trata por separado la época colonial y la nacional.

En relación con el siglo XIX, Trabulse continúa manteniendo la tesis de que "la guerra de Independencia fue el principio de una profunda crisis en los estudios científicos mexicanos", agregando que "ello se reflejó en las publicaciones y en la iconografía científica de la primera década de vida independiente". El período del Segundo Imperio continúa prácticamente ausente y los de la República Restaurada y el Porfiriato destacan la riqueza iconográfica que acompañó los textos científicos que proliferaron en el pasado fin de siglo. Esta parte del análisis revela el dominio que adquiriera el autor en su obra anterior José María Velasco. Un paisaje de la ciencia en México, que da cuenta de las técnicas de la ilustración científica y su práctica en nuestro país durante el siglo XIX, junto con la presentación de uno de los pintores más importantes de la época, José María Velasco ${ }^{128}$. Este libro contiene buena parte de los textos que se incluyen en el primero que reseñamos, y se acompaña con un apéndice documental compuesto por los escritos científicos del pintor. Impresas con el lujo que corresponde al género del que se ocupan, ambas obras revelan el generoso resultado estético que se alcanzó al traducir las verdades de la naturaleza a su representación visual ${ }^{129}$.

126 Ibidem, p. 35.

127 Ibidem, p. 41.

128 TRABulSe, E. (1992): José María Velasco. Un paisaje de la ciencia en México, Toluca, Instituto Mexiquense de Cultura, $332 \mathrm{p}$.

129 Entre los cultivadores del género se cuentan: GERMÁN, M. T. (1995): Iconografía botánica (Siglo XIX) del Herbario Nacional, UNAM-Instituto de Biología, 19 p. ils. y HERRÁN, J. de. (1993): "Pintores científicos mexicanos" en Ciencia y Desarrrollo, nueva época, XIX, 82-83. El primero contiene dibujos y acuarelas de los pintores José María Velasco, Adolfo Tenorio, Adrían Unzueta, del médico Clemente Robles y del dibujante Francisco Moctezuma, que se acompañan con datos biográficos de los tres primeros. El segundo es un breve texto de divulgación que destaca las obras de José María Velasco y Hermenegildo Bustos que inmortalizaron el cometa de 1882. 


\section{RECAPITULACIÓN}

La reseña que hemos elaborado revela a grandes rasgos el zigzagueante camino que ha seguido la investigación histórica de la ciencia mexicana del siglo XIX y su articulación con el proceso de conformación de la disciplina académica que nos ocupa.

En relación con este proceso, la historiografía de la ciencia mexicana en general - y la del siglo XIX en particular - se ha desarrollado en tres grandes momentos. El primero agrupa las historias que elaboraron los científicos del pasado fin de siglo con el fin de legitimar su quehacer, integrándolo en el movimiento universal de la ciencia y dentro de la añeja tradición histórica de la que eran herederos. El segundo está conformado con los trabajos que se derivaron del proyecto de sistematizar los estudios históricos sobre la ciencia mexicana que se impulsó en los años sesenta, y que se nutrió del movimiento que estableció a la historia de la ciencia como disciplina académica en otras latitudes. El tercero constituye la materialización de aquel proyecto en los primeros trabajos profesionales que se publicaron en México en los años setenta, y que sirvieron como punto de partida para la reformulación sobre la ciencia mexicana del siglo XIX, que comenzó a dar frutos en la última década.

En términos de la comprensión global de la centuria, las historias generales - de Gortari y Trabulse - excluyen el estudio de las actividades que se desarrollaron en determinados períodos, en virtud de los enfoques metodológicos que las sustentan. El enfoque de la historia social de las ciencias, por su parte, ha generado una gran cantidad de trabajos en torno a las instituciones científicas creadas a lo largo del siglo, y se ha constituído en la vía de integración de períodos y objetos que estaban ausentes en otras perspectivas. Al mismo tiempo, la historiografía más reciente se ha diversificado en objetos concretos - las disciplinas, las publicaciones y las instituciones individuales-cuya suma no alcanza aún a integrar una visión completa del período ${ }^{130}$.

Este panorama pone en evidencia las tareas que deberemos enfrentar en los próximos años, entre las que destaca la urgencia de profundizar y ampliar los estudios de los períodos recién recuperados. También es imprescindible proseguir las investigaciones sobre el desenvolvimiento de cada una de las disciplinas científicas que se practicaron a lo largo del siglo. Es preciso continuar sobre la línea de la biografía científica, y abrirla hacia la prosopografía; romper con el centralismo que continúa dominando en la historiografía, a través de la consolidación de los estudios de la historia regional de las ciencias; emprender nuevas investigaciones sobre la educación científica; abordar los procesos de la difusión de los avances de la ciencia del siglo XIX en México y empezar a discutir sobre los públicos de la ciencia en aquel período. También es urgente elaborar la reinterpretación del positivismo en México

\footnotetext{
130 Desde luego, la fragmentación disciplinar se explica como el natural resultado de la especialización que se generó en las propias disciplinas científicas en el siglo XIX, y que deriva en la necesaria especialización de sus historiadores.
} 
en términos del papel histórico que desempeñó la práctica científica como sustento del proceso de modernización del país, para dejar atrás la perspectiva tradicional que limita el papel de la ciencia del pasado fin de siglo, a un mero recurso ideológico que sostuvo a la Dictadura.

Por último, la evolución historiográfica que hemos reseñado — con todo y sus grandes ausencias-, revela que la ciencia del siglo XIX ha remontado la condena post-revolucionaria, dejando atrás la "historia secreta de México". El proceso de su recuperación es fruto de los esfuerzos crecientes y sostenidos de aquéllos que, buscando las claves para la recuperación de nuestro pasado científico, promovieron el tránsito de la historia de las ciencias de su status de curiosidad intelectual e instrumento legitimador a su constitución como disciplina académica. Esto último ha redituado fundamentalmente en la reinterpretación del siglo XIX, que beneficiará no solamente a los nuevos especialistas, sino que contribuirá a la comprensión general del pasado mexicano. 